\section{Endoscopic treatment of colonic diverticular bleeding using an over-the-scope clip}

A 73-year-old woman who was receiving dual antiplatelet therapy (acetylsalicylic acid and prasugrel) after coronary stenting presented with severe hematochezia. Immediate colonoscopy without bowel preparation, using a CF-HQ190I colonoscope (Olympus Medical Systems, Tokyo, Japan) with a transparent cap (D-20114304 , Olympus), revealed active and sustained bleeding from a diverticulum in the sigmoid colon ( $\nabla$ Fig. 1 a).

After the bleeding site had been marked with an endoclip ( Fig.1 b), the colonoscope was removed. An over-the-scope clip (OTSC system set $12 / 6 \mathrm{t}$, length $1650 \mathrm{~mm}$; Ovesco Endoscopy, Tübingen, Germany) was attached onto a gastroscope (GIF-1TQ160; Olympus), which was then reinserted. This change of scope was necessary because of the scope diameter needed for the OTSC system. The

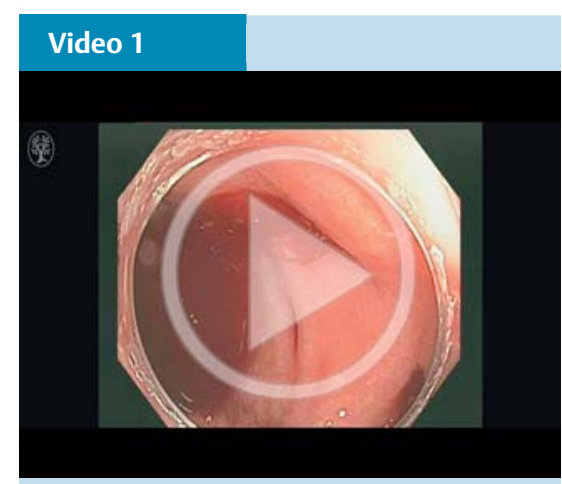

Endoscopic view showing active bleeding sfrom a sigmoid diverticulum, which is stopped immediately by the placement of an over-thescope clip (OTSC). bleeding diverticulum was suctioned into the transparent cap of the OTSC system and the clip was released, which led to immediate cessation of the bleeding ( Fig.1c; Video 1). The procedure time was 15 minutes and the patient's further course was uneventful.

Diverticular bleeding is the most common cause of lower gastrointestinal bleeding (GIB). The identification of a bleeding diverticulum as the source is possible in about $20 \%$ of cases and makes endoscopic therapy possible [1]. Several endoscopic treatment methods, such as epinephrine injection, coagulation therapy, clipping, or band ligation, have been used. Treatment failures, complications, and episodes of rebleeding have been reported for all of these techniques and the ideal treatment method has not yet been defined [1 - 3].

The OTSC system has been developed for closure of perforations, leaks, and fistulas. Recently OTSCs have also been shown to be a highly effective treatment option for patients with severe GIB as a rescue therapy, but also for first-line treatment. Data are mainly restricted to nonvariceal upper GIB with limited data available on lower GIB [4]. Only a few case reports have described the use of OTSCs for diverticular bleeding in the duodenum and the colon $[4,5]$. Our case demonstrates that the OTSC system is an effective and easy-tohandle first-line treatment for severe colonic diverticular hemorrhage.

\section{Endoscopy_UCTN_Code_TTT_1AQ_2AZ}

\section{Andreas Probst, Georg Braun, Stefan Goelder, Helmut Messmann}

Department of Gastroenterology, Klinikum Augsburg, Augsburg, Germany

\section{References}

1 Jensen DM, Machicado GA, Jutabha $R$ et al. Urgent colonoscopy for the diagnosis and treatment of severe diverticular hemorrhage. NEJM 2000; 342: 78-82

2 Hokama A, Uehara T, Nakayoshi T et al. Utility of endoscopic hemoclipping for colonic diverticular bleeding. Am J Gastroenterol 1997; 92: 543-546

3 Ishii N, Setoyama T, Deshpande GA et al. Endoscopic band ligation (EBL) for colonic diverticular hemorrhage. Gastrointest Endosc 2012; 75: $382-387$

4 Manta R, Galloro G, Mangiavillano B et al. Over-the-scope clip (OTSC) represents an effective endoscopic treatment for acute GI bleeding after failure of conventional techniques. Surg Endosc 2013; 27: 3162 -3164

5 Fujihara S, Mori H, Kobara $H$ et al. Use of an over-the-scope clip and a colonoscope for complete hemostasis of a duodenal diverticular bleed. Endoscopy 2015; 47 (Suppl. 01): E236 -E237

\section{Bibliography}

Dol http://dx.doi.org/

10.1055/s-0042-106167

Endoscopy 2016; 48: E160

(c) Georg Thieme Verlag KG

Stuttgart · New York

ISSN 0013-726X

\section{Corresponding author}

Andreas Probst, MD

III. Medizinische Klinik

Klinikum Augsburg

Stenglinstrasse 2

86156 Augsburg

Germany

Fax: +49-821-4003331

andreas.probst@klinikum-augsburg.de
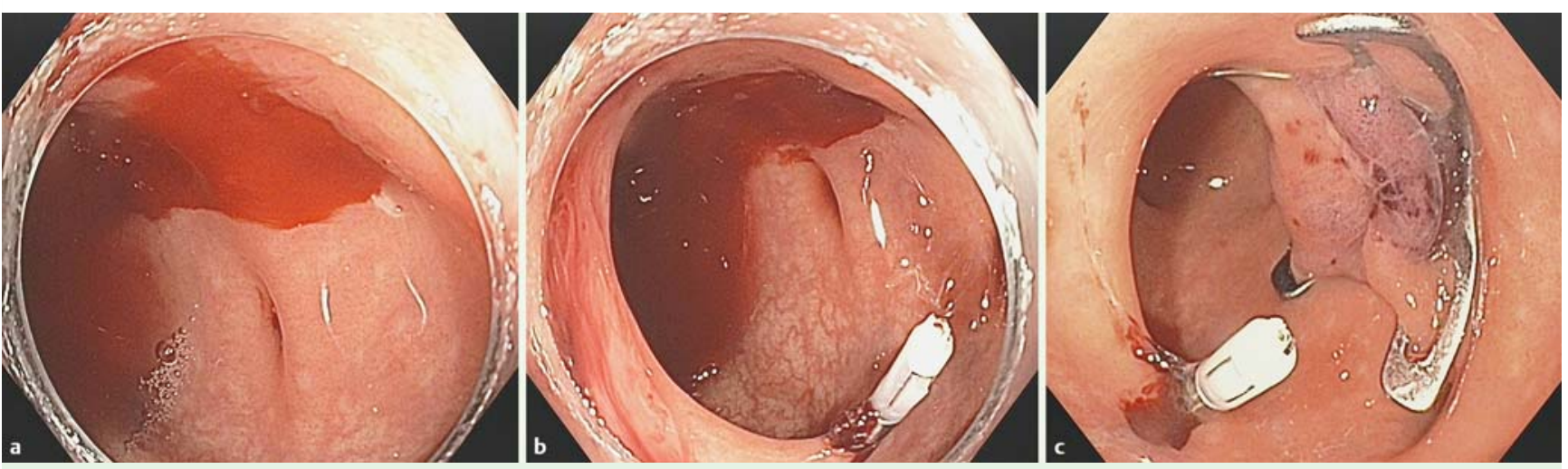

Fig. 1 Endoscopic views showing: a active diverticular bleeding in the sigmoid colon; $\mathbf{b}$ a conventional endoclip in place to mark the bleeding region; c the over-the-scope clip (OTSC) in position, which led to immediate hemostasis after its release. 